\title{
Advanced techniques improve the performance of myocardial perfusion imaging
}

\author{
Geraint Morton", Masaki Ishida, Andreas Schuster, Tobias Schaeffter, Amedeo Chiribiri, Eike Nagel \\ From 15th Annual SCMR Scientific Sessions \\ Orlando, FL, USA. 2-5 February 2012
}

\begin{abstract}
Background
Technical advances in cardiac magnetic resonance (CMR) perfusion imaging, particularly accelerated data acquisition methods, allow myocardial perfusion imaging with unprecedented spatio-temporal resolution. However, it is not clear how implementation of these advances affects perfusion image quality and artefacts and signal and contrast to noise ratios (SNR and CNR).
\end{abstract}

\section{Methods}

A standard ultrafast gradient echo perfusion sequence (st-GrE) was compared with an advanced kt-accelerated steady state free precession sequence (kt-SSFP) at $1.5 \mathrm{~T}$ in a hardware perfusion phantom, healthy volunteers $(\mathrm{n}=16)$ and patients $(\mathrm{n}=31)$ with known or suspected coronary artery disease. Volunteers had both sequences at rest in alternating order. Patients underwent stress imaging with either st-GrE (15) or kt-SSFP (16) prior to $\mathrm{X}$-ray coronary angiography.

The phantom was used to generate signal intensity curves and noise maps for SNR and CNR analysis. Human images were analysed by a blinded observer using a nominal scale for quality (0 non-diagnostic, 1 poor, 2 moderate, 3 good, 4 excellent) and respiratory artefacts ( 0 non-diagnostic, 1 severe, 2 moderate, 3 minor, 4 nil) and also for the presence of CAD in patients. Other analyses included the extent (\% affected segments), transmurality (1: 1-25\%, 2: 26-50\%, 3: 51$75 \%, 476-100 \%$ ) and duration (frames) of dark rim artefacts (DRA). Segmental SNR and CNR were also quantified using the mid ventricular slice in volunteers.

\section{Results}

Phantom studies demonstrated comparable SNR and CNR for both sequences: (SNR 54.7 \& 53.9 and CNR
$24.1 \& 22.8$ for st-GrE and kt-SSFP respectively). In normal hearts kt-SSFP imaging resulted in significantly improved image quality $(\mathrm{p}=0.003)$, SNR $(21.0 \pm 6.7$ vs. $18.8 \pm 6.6 ; \mathrm{p}=0.009), \mathrm{CNR}(15.4 \pm 6.1$ vs. $14.0 \pm 6.0$; $\mathrm{p}=0.034)$ and a reduced extent $(\mathrm{p}=<0.0001)$ and transmurality $(\mathrm{p}=0.0001)$ of DRA. In patients kt-SSFP imaging resulted in significantly improved image quality $(\mathrm{p}=0.012)$, and a reduced extent $(\mathrm{p}=<0.0001)$, duration $(\mathrm{p}=0.004)$ and transmurality $(\mathrm{p}=<0.0001)$ of DRA. Sensitivity and specificity for the detection of CAD against $\mathrm{X}$ ray angiography was comparable with both sequences. There was a non-significant trend towards increased respiratory artefacts with kt-SSFP in both patients and volunteers.

\section{Conclusions}

Advanced high spatio-temporal resolution CMR perfusion imaging using a kt-SSFP technique results in significantly improved image quality, SNR and CNR and a reduction in the extent and transmurality of DRA compared to a standard sequence.

\section{Funding}

This work was supported by a European Union Grant (Grant number 224495 to GM, EN); the British Heart Foundation (Research Excellence Award RE/08/003 and FS/10/029/28253 to AS, EN); the Biomedical Research Centre (grant number BRC-CTF 196 to AS, EN) and the Wellcome Trust and EPSRC (grant number WT 088641/Z/09/Z to AC, EN).

Published: 1 February 2012

King's College London, London, UK

(c) 2012 Morton et al; licensee BioMed Central Ltd. This is an open access article distributed under the terms of the Creative Commons 
Table 1 Perfusion sequence parameters

\begin{tabular}{ccc}
\hline Parameter & st-GrE & kt-SSFP \\
\hline Acquired spatial resolution & $1.7 \times 1.9 \times 10 \mathrm{~mm}$ & $2.6 \times 2.8 \times 10 \mathrm{~mm}$ \\
Echo time (TE) & Shortest (range 1.61-1.91ms) & Shortest (range 1.29-1.59ms) \\
Repetition time (TR) & Shortest (range 3.6-3.9ms) & Shortest (range 2.59-3.18ms) \\
Flip angle & $18^{\circ}$ & $50^{\circ}$ \\
Prepulse & $90^{\circ}$ & $90^{\circ}$ \\
Prepulse delay & $100 \mathrm{~ms}$ & $100 \mathrm{~ms}$ \\
Acceleration technique & SENSE: factor 2 & kt-BLAST: factor 5 with 11 training profiles (effective k-t factor of 3.8) \\
\hline
\end{tabular}

Table 2 Sequence comparison

\begin{tabular}{|c|c|c|c|c|c|c|c|c|c|c|}
\hline \multirow[b]{3}{*}{ Image quality } & \multicolumn{5}{|c|}{ Volunteers } & \multicolumn{5}{|c|}{ Patients } \\
\hline & \multicolumn{2}{|c|}{ st-GRE } & \multicolumn{2}{|c|}{ kt-SSFP } & \multirow[t]{2}{*}{$p$ value } & \multicolumn{2}{|c|}{ st-GRE } & \multicolumn{2}{|c|}{ kt-SSFP } & \multirow[t]{2}{*}{$p$ value } \\
\hline & $\mathrm{n}$ & $\%$ & $n$ & $\%$ & & $\mathrm{n}$ & $\%$ & $\mathrm{n}$ & $\%$ & \\
\hline 0 non-diagnostic & 1 & $6 \%$ & 0 & & & 0 & & 0 & & \\
\hline 1 poor & 0 & & 0 & & & 3 & $10 \%$ & 0 & & \\
\hline 2 moderate & 12 & $75 \%$ & 3 & $19 \%$ & 0.003 & 12 & $40 \%$ & 2 & $6 \%$ & 0.012 \\
\hline 3 good & 3 & $19 \%$ & 12 & $75 \%$ & & 12 & $40 \%$ & 17 & $53 \%$ & \\
\hline 4 excellent & 0 & & 1 & $6 \%$ & & 3 & $10 \%$ & 13 & $41 \%$ & \\
\hline \multicolumn{11}{|l|}{ Respiratory artefacts } \\
\hline 0 non-diagnostic & 0 & & 0 & & & 0 & & 0 & & \\
\hline 1 severe & 0 & & 1 & $6 \%$ & & 0 & & 2 & $6 \%$ & \\
\hline 2 moderate & 3 & $19 \%$ & 5 & $31 \%$ & 0.07 & 7 & $23 \%$ & 7 & $22 \%$ & 0.17 \\
\hline 3 mild & 7 & $44 \%$ & 7 & $44 \%$ & & 8 & $27 \%$ & 16 & $50 \%$ & \\
\hline 4 nil & 6 & $38 \%$ & 3 & $19 \%$ & & 15 & $50 \%$ & 7 & $22 \%$ & \\
\hline \multicolumn{11}{|l|}{ Dark rim artefact } \\
\hline Extent(\%) & $39 \pm 13$ & & $15 \pm 12$ & & $<0.0001$ & $33 \pm 14$ & & $12 \pm 10$ & & $<0.0001$ \\
\hline Transmurality & $1.83 \pm 0.58$ & & $1.02 \pm 0.06$ & & $<0.0001$ & $1.57 \pm 0.40$ & & $1.07 \pm 0.17$ & & $<0.0001$ \\
\hline Duration & $10.6 \pm 3.56$ & & $9.7 \pm 2.51$ & & 0.373 & $10.8 \pm 3.7$ & & $8.0 \pm 2.7$ & & 0.004 \\
\hline
\end{tabular}

doi:10.1186/1532-429X-14-S1-P12

Cite this article as: Morton et al:: Advanced techniques improve the performance of myocardial perfusion imaging. Journal of Cardiovascular Magnetic Resonance 2012 14(Suppl 1):P12.

Submit your next manuscript to BioMed Central and take full advantage of:

- Convenient online submission

- Thorough peer review

- No space constraints or color figure charges

- Immediate publication on acceptance

- Inclusion in PubMed, CAS, Scopus and Google Scholar

- Research which is freely available for redistribution

Submit your manuscript at www.biomedcentral.com/submit
C Biomed Central 